\title{
Measuring clinical outcomes in children with pediatric acute-onset neuropsychiatric syndrome: data from a 2-5 year follow-up study
}

Caroline De Visscher ${ }^{1,2,3^{*}}$, Eva Hesselmark ${ }^{1,2}$, Daniel Rautio ${ }^{1,2}$, Ida Gebel Djupedal ${ }^{2}$, Maria Silverberg ${ }^{2}$, Selma Idring Nordström ${ }^{1,2}$, Eva Serlachius ${ }^{1,2}$ and David Mataix-Cols $s^{1,2}$

\begin{abstract}
Background: It is unclear how to best measure the complex symptom presentation of pediatric acute-onset neuropsychiatric syndrome (PANS).

Methods: Well-characterized participants of a $2-5$ year follow-up study ( $n=34 ; 56 \%$ male) underwent clinical evaluations and completed scales assessing global symptom severity, functional impairment and specific psychiatric symptoms. We explored inter-correlations between the measures and used intraclass correlation coefficients to evaluate the agreement between clinician-, parent- and child ratings of the same constructs.

Results: Ratings on symptom-specific measures varied largely between participants. Agreement between informants was excellent on functional scales, fair-to-moderate on global severity scales and mixed on symptomspecific scales. Clinician-rated global and functional measures had stronger inter-correlations with parent- and childrated functional measures than with symptom-specific measures.

Conclusions: General instruments assessing global severity and functioning are well suited for the assessment and follow-up of PANS, but should be complemented by symptom-specific scales representative of core symptoms.
\end{abstract}

Keywords: PANS, PANDAS, OCD, Tourette, Immunopsychiatry

\section{Introduction}

Pediatric acute-onset neuropsychiatric syndrome (PANS) is a descriptive entity consisting of acute-onset OCD and/ or eating disorder accompanied by a wide range of secondary psychiatric and somatic symptoms [1]. Initial and recurring symptoms may be severe and lead to significant loss of function $[2,3]$. There are no clearly established

\footnotetext{
* Correspondence: caroline.de.visscher@momentpsykologi.se

${ }^{1}$ Centre for Psychiatry Research, Department of Clinical Neuroscience, Karolinska Institutet, Stockholm, Sweden

${ }^{2}$ Stockholm Health Care Services, Region Stockholm, CAP Research Center,

Gävlegatan 22, SE-113 30, Stockholm, Sweden

Full list of author information is available at the end of the article
}

evidence-based treatments for PANS [4] but the longterm prognosis is generally positive, with approximately two thirds of patients presenting with minimal or no symptoms $2-5$ years after initial presentation [5]. However, approximately one third of patients have a chronic clinical course and require additional treatment [5].

Several measures have been proposed for the characterization of PANS patients [6-8]. The wide range of symptoms represented within the PANS construct constitutes a challenge for both daily clinic work and for the design of clinical trials [4]. At least two clinicianrated instruments or symptom checklists have been specifically developed for PANS, but their administration is

(c) The Author(s). 2021 Open Access This article is licensed under a Creative Commons Attribution 4.0 International License, which permits use, sharing, adaptation, distribution and reproduction in any medium or format, as long as you give appropriate credit to the original author(s) and the source, provide a link to the Creative Commons licence, and indicate if changes were made. The images or other third party material in this article are included in the article's Creative Commons licence, unless indicated otherwise in a credit line to the material. If material is not included in the article's Creative Commons licence and your intended use is not permitted by statutory regulation or exceeds the permitted use, you will need to obtain permission directly from the copyright holder. To view a copy of this licence, visit http://creativecommons.org/licenses/by/4.0/ The Creative Commons Public Domain Dedication waiver (http://creativecommons.org/publicdomain/zero/1.0/) applies to the data made available in this article, unless otherwise stated in a credit line to the data. 
time-consuming, their items cannot be easily collated to calculate total scores, and their psychometric properties have not been established $[9,10]$. The use of gold standard measures for specific psychiatric symptoms, such as the Children's Yale-Brown Obsessive Compulsive Scale (CY-BOCS) [11] or the Yale Global Tic Severity Scale (YGTSS) [12, 13] as single outcome measures is also problematic because they only capture specific symptom clusters and their use may result in both an over- or underestimation of treatment responders [4, 14]. Conversely, trying to assess every individual symptom cluster may result in an overwhelming number of rating scales for the families to complete, reducing the quality of the collected data and the willingness to participate in research.

Previous experience from our PANS cohort $[3,5]$ suggested a potential discrepancy between clinician-rated measures of global functioning, disease severity and improvement scales on the one hand, and subjective reports from parents on the other. It is possible that frequently used instruments may not capture the full extent of the patients' difficulties [5]. For some families this may result in frustration and a perceived lack of understanding of the true impact of PANS from the medical community.

In this study, we aimed to investigate the suitability of standard clinical measures for the assessment and follow-up of children with PANS, and formally assess the degree of agreement between multiple informants (child, parent and clinician ratings). Ultimately, we aim to shed some light on the optimal ways to measure the complex presentation of this patient group.

\section{Methods \\ Participants}

Participants were consecutive referrals to a multidisciplinary immunopsychiatry outpatient clinic in Stockholm, Sweden, who were previously included in a Swedish PANS cohort $[3,5]$. Cohort members who had a minimum of 2 years since inclusion were eligible for participation in a follow-up study, regardless of whether they were still active patients in the clinic or not. The current analyses are based on data collected as part of the follow-up study, i.e. 2-5 years after first assessment [5]. All participants met strict PANS criteria at first assessment.

Parents/guardians of the participants gave written informed consent to participate in the study, which was approved by the Regional Ethics Review Board in Stockholm (reference number EPN 2015/1977-31/4 (2019-02132)). All procedures performed in the study were in accordance with the 1964 Declaration of Helsinki and its later amendments.

\section{Clinical evaluations}

A child and adolescent psychiatrist conducted a 2-h faceto-face assessment, including a standardized patient- and parent interview and clinician-rated measures of symptoms and general functioning. Child- and parent-rated measures of specific symptoms and general functioning were completed prior to the visit to the clinic. Some of the participating children were very young, but parents were instructed to help their children as little as possible when compiling their responses. In the few cases where an item on a scale was missing, these were completed via a telephone call with the parent. If a child-rated item was missing, the parent was instructed to report the missing item in collaboration with the child.

The specific measures were chosen based on our clinical experience and recommendations from the 2013 PANS Consensus Conference [7], and can be classified as measures of global symptom severity and adaptive functioning, and symptom-specific measures.

\section{Measures of global symptom severity and adaptive functioning}

The Clinical Global Impressions-Severity scale (CGI-S) is a clinician-rated scale measuring the current severity of a patients psychiatric illness in general, on a 7 point single-item scale [15]. CGI-S scores range from 'normal' (score 1) to 'extremely ill' (score 7). It is a widely used, validated clinical outcome measure in psychiatry [16]. In addition to the original clinician-rated version, the CGI$S$ was adapted for its use as a self-report measure, resulting in parent- and child-rated versions of the scale (see Supplemental material).

The Strengths and Difficulties Questionnaire - Parent -/Self-rated version (SDQ-P/S) is a validated parent- and child-rated, behavioral screening questionnaire consisting of five subscales, four measuring difficulties (hyperactivity, emotional symptoms, conduct problems and peer problems) and one measuring strengths (pro-social behavior). Items are scored from 'not true' (score 0) to 'certainly true' (score 2), with a maximum total difficulty score of 40. A higher total difficulty score indicates a higher symptom burden and a lower global functioning. A total difficulty score of 14 has been suggested as a cut-off. SDQ-S is adapted for 11-16 year old children and adolescents and was therefore only used for this age group in the study $[17,18]$.

The Children's Global Assessment Scale (CGAS) is a clinician-rated, extensively validated, single-item measure of general functioning. The scale ranges from 1 to 100 , with higher scores indicating a higher (better) level of general functioning [19]. The assessment should be made by a specifically trained child and adolescent psychiatrist or psychologist after a thorough clinical assessment and reflect the most impaired level during a 
specified time period of 1 month, regardless of treatment and/or prognosis [20, 21].

KIDSCREEN-10 - Parent/Youth version is a parentand child-rated screening instrument measuring wellbeing and health-related quality of life for children and adolescents. The scale contains 10 items, using a 5-point response scale, with a maximum score of 50. A higher score indicates higher (better) health-related quality of life. An additional item measuring general well-being is scored separately, using a 5-point scale, from 'bad' (score 1) to 'excellent' (score 5) [22, 23].

The Work and Social Adjustment scale-Parent/Youth version $(W S A S-P / Y)$ is a brief and reliable parent- and child-rated measure of educational, work and social adjustment in children and adolescents. The scale includes five items related to everyday activities (school and employment, everyday activities, social activities, leisure time, and family/relationships), scored from 'not impaired at all' (score 0) to 'severely impaired' (score 8), with a maximum score of 40 . WSAS-P/Y has high internal consistency and is sensitive to change $[24,25]$.

\section{Symptom-specific measures}

The Children's Yale-Brown Obsessive Compulsive Scale (CY-BOCS) and the Yale Global Tic Severity Scale (YGTSS) are clinician-rated instruments to quantify the severity of OCD and tic disorder symptoms, respectively [11-13]. Both scales have excellent psychometric properties and are routinely employed in clinical practice and clinical trials. Higher total scores indicate a higher symptom burden, and clinically significant levels of OCD and tic symptoms are generally considered to be reached at CY-BOCS > 15 and YGTSS > 30 [12, 26, 27].

The Obsessive Compulsive Inventory-Child Version $(\mathrm{OCI}-\mathrm{CV})$ is a 21-item child-rated self-report measure of OCD symptom severity that correlates moderately well with clinician-rated measures of OCD symptoms. It consists of seven sub-scales (doubting/checking, obsessing, hoarding, washing, ordering and neutralizing). Items are scored from 'never' (score 0) to 'always' (score 2), with a maximum score of 42 . A higher score indicates more severe symptoms $[28,29]$.

The Short Moods and Feelings Questionnaire - Parent/Child version (SMFQ-P/C) is a 13-item parent- and child-rated screening tool for depression in children and adolescents, developed from the longer 34-item version Moods and Feelings Questionnaire (MFQ). Both versions of the scale have been extensively validated in community and clinical samples. Responses are rated using a 3-point scale from 'not true' (score 0) to 'true' (score 2), with a maximum score of 26 . A higher score indicates more severe depressive symptoms. Suggested cut-offs for girls are $>16$ and for boys $>5$ when parentor self-rated [30, 31].
The Separation Anxiety Avoidance Inventory - Parent/ Child version $(S A A I-P / C)$ is a validated 12 -item parentand child-rated measure of avoidance behavior in separation situations. Each item is scored from 'never' (score 0) to 'always' (score 4), with a maximum score of 48. A higher total score indicates more severe avoidance behavior [32].

The Insomnia Severity Index - Child and adolescent version (ISI-C) is a 7-item child-rated measure assessing insomnia severity using a 5-point scale from 'not at all' (score 0) to 'extremely' (score 4), with a maximum score of 28. A high total score indicates greater insomnia severity, with scores 15 and above indicating clinical insomnia [33, 34].

The Autism Spectrum Quotient Child/Adolescent version-10 (AQ-10) is a 10-item parent-rated instrument initially developed as a tool to aid referral decision making for autism spectrum disorder (ASD) evaluation. The maximum score is 10 and scores 6 or above are considered a positive indication of ASD [35]. Previous data has shown a high incidence of neuropsychiatric symptoms in PANS-patients during follow-up, highlighting the importance of using an ASD screening tool even for previously assessed patients [5].

The Swanson, Nolan and Pelham scale (SNAP-IV) is a parent-rated scale assessing attention deficit and hyperactivity (ADHD)-related symptoms and oppositional defiant disorder (ODD) [36, 37]. It is a frequently used tool in treatment studies as well as in daily clinic work following-up ADHD treatment. The SNAP-IV exists in different versions depending on items rated. The version most frequently used in Sweden is a 30-item version rating ADHD inattention, ADHD hyperactivity/impulsivity and ODD. Each item is scored from 'not at all' (score 0) to 'very much' (score 4), with a maximum total score of 120. Mean scores for each sub-section of the scale are also calculated [38].

The Eyberg Child Behavior Inventory (ECBI) is a 36item parent-rated scale of disruptive behavior problems in children, divided in an intensity scale measuring the frequency of a behavior and a problem scale measuring if the parent perceives the behavior as a problem. The maximum score on the intensity scale is 252 , and scores $>130$ are considered clinically significant. The maximum score on the problem scale is 36 , with scores $>14$ indicating significant parental distress $[39,40]$.

\section{Statistical analysis}

For each scale and subscale, we calculated descriptive statistics (median, mean and SD). Intraclass correlation coefficients (ICCs) were calculated to establish the degree of agreement between clinician-, parent- and child ratings of the same rating scale. Because the set of raters was different for each target (i.e. same clinician but 
different set of parent and child rating each patient), ICC $(1, k)$ estimates and their 95\% confident intervals were calculated based on a mean-rating by $k$ number of raters $(k=3$ if clinician, parent and child; $k=2$ if clinician and parent, clinician and child or parent and child), absolute-agreement, one-way random effects model [41]. Individual ICCs (the agreement between different raters on the same individual/participant) are reported. ICC values $<0.40$ correspond to poor agreement, values between 0.40 and 0.59 to fair agreement, values between 0.60 and 0.74 to good agreement, and values $>0.75$ to excellent agreement [42]. Correlation coefficients were calculated in order to measure the degree of association between measures. Because the data were not always normally distributed, Spearman rank correlation was used. Correlation coefficients between 0 and 0.29 represent poor association, $0.30-0.49$ fair association, $0.50-0.79$ moderate association and $>0.80$ a very strong association $[43,44]$.

All statistical analyses were conducted using STATA software (version STATA/IC15.1 for Mac, StataCorp
LLC, Texas, USA). $P$-values below 0.05 were considered to be statistically significant.

\section{Results}

Sample characteristics

Thirty-four out of 46 eligible PANS patients consented to participate in the follow-up study and provided data. Median age at follow-up was 11.5 years (range 6.7-17.1) and $19(56 \%)$ of the participants were male. Further details on the clinical characteristics of the cohort, including duration of illness, comorbidities, current symptoms, family history of psychiatric and autoimmune disease can be found in a previous publication [5].

\section{Descriptive statistics}

At a group level, median and mean scores for most global and specific symptom scales generally indicated lowto-moderate symptom severity and high level of functioning. However, there was substantial variability in the data, suggesting that some individuals experienced

Table 1 Descriptive statistics of global severity and adaptive function rating scales at follow-up $(n=34)$

\begin{tabular}{|c|c|c|c|}
\hline & $\mathrm{n}$ & median (range) & mean (SD) \\
\hline CGI-S clinician & 34 & $3(1-6)$ & $2.8(1.4)$ \\
\hline CGI-S parent & 34 & $2(0-5)$ & $2.4(1.5)$ \\
\hline CGI-S child & 33 & $1(0-6)$ & $2.2(1.6)$ \\
\hline SDQ- $P^{b}$ total & 34 & $9.5(3-23)$ & $11.1(6.4)$ \\
\hline SDQ-P emotional symptoms & 34 & $3.5(0-10)$ & $4(2.3)$ \\
\hline SDQ-P hyperactivity/inattention & 34 & $4.5(0-10)$ & $4.1(3.1)$ \\
\hline SDQ-P peer problems & 34 & $1(0-6)$ & $1.6(1.7)$ \\
\hline SDQ-P conduct problems & 34 & $1(0-6)$ & $1.4(1.6)$ \\
\hline SDQ-P prosocial behavior & 34 & $9(4-10)$ & $8.2(1.8)$ \\
\hline SDQ-S $\mathrm{S}^{\mathrm{C}}$ total & 22 & $10(4-18)$ & $10.3(4.5)$ \\
\hline SDQ-S emotional symptoms & 22 & $4(0-10)$ & $3.8(2.3)$ \\
\hline SDQ-S hyperactivity/inattention & 22 & $3.5(0-8)$ & $3.9(2.2)$ \\
\hline SDQ-S peer problems & 22 & $1.5(0-6)$ & $1.5(1.4)$ \\
\hline SDQ-S conduct problems & 22 & $1(0-5)$ & $1.3(1.2)$ \\
\hline SDQ-S prosocial behavior & 22 & $9(6-10)$ & $8.7(1.2)$ \\
\hline $\mathrm{CGAS}^{\mathrm{d}}$ & 34 & $61(28-80)$ & $60.9(13.5)$ \\
\hline KIDSCREEN-10 parent total & 34 & $38.5(25-47)$ & $37.5(5.8)$ \\
\hline KIDSCREEN-10 parent general well-being & 34 & $3(1-5)$ & $3.1(1.1)$ \\
\hline KIDSCREEN-10 child total & 33 & $39(24-46)$ & $38.3(6.1)$ \\
\hline KIDSCREEN-10 child general well-being & 33 & $3(1-5)$ & $3.3(1)$ \\
\hline WSAS-Pe & 34 & $12.5(0-30)$ & $12.9(9.2)$ \\
\hline WSAS-Y $Y^{f}$ & 33 & $9(0-31)$ & $10.8(9.7)$ \\
\hline
\end{tabular}

${ }^{\mathrm{a} C G I-S}$ Clinical Global Impression-Severity scale

${ }^{b} S D Q-P$ Strengths and Difficulties Questionnaire-Parent rated

'SDQ-S Strengths and Difficulties Questionnaire-Self rated

${ }^{d}$ CGAS Children's Global Assessment Scale

eWSAS-P Work and Social Adjustment Scale-Parent version

fWSAS- $Y$ Work and Social Adjustment Scale-Youth version 
Table 2 Descriptive statistics of symptom-specific rating scales at follow-up $(n=34)$

\begin{tabular}{|c|c|c|c|c|}
\hline & $\mathrm{n}$ & $\%$ & median (range) & mean (SD) \\
\hline$\overline{C Y-B O C S^{a}}$ & 34 & & $8(0-30)$ & $8.2(8)$ \\
\hline YGTSS $^{b}$ & 34 & & $4.5(0-65)$ & $10.4(14)$ \\
\hline $\mathrm{OCl}-\mathrm{CV}^{\mathrm{C}}$ & 33 & & $11(0-18)$ & $9.5(5.1)$ \\
\hline SMFQ-Pd & 34 & & $4.5(0-14)$ & $5.9(4.4)$ \\
\hline SMFQ-C & 31 & & $4(1-19)$ & $5.5(4.7)$ \\
\hline SAAI- $\mathrm{P}^{f}$ & 33 & & $10(0-35)$ & $12.5(10.9)$ \\
\hline SAAI-C ${ }^{g}$ & 33 & & $8(0-36)$ & $10.6(9.4)$ \\
\hline$|S|-C^{h}$ & 33 & & $5(0-18)$ & $5.9(4.6)$ \\
\hline$A Q-10^{i}$ & 31 & & $3(0-8)$ & $3(2)$ \\
\hline SNAP-IV & 34 & & $18.5(0-57)$ & $21.9(14.3)$ \\
\hline SNAP-IV inattention & 34 & & $1(0-2.3)$ & $1.1(0.7)$ \\
\hline SNAP-IV hypertactivity/impulsivity & 34 & & $0.4(0-2.4)$ & $0.7(0.7)$ \\
\hline SNAP-IV ODD & 34 & & $0.5(0-2.1)$ & $0.7(0.6)$ \\
\hline$E C B I^{k}$ intensity scale & 33 & & $90(41-169)$ & $95.9(34.5)$ \\
\hline ECBI problem scale & 34 & & $7(0-25)$ & $7.9(7.4)$ \\
\hline
\end{tabular}

${ }^{a} C Y$-BOCS Children's Yale-Brown Obsessive Compulsive Scale

${ }^{\text {b } Y G T S S ~ Y a l e ~ G l o b a l ~ T i c ~ S e v e r i t y ~ S c a l e ~}$

'OCI-CV Obsessive Compulsive Inventory-Child Version

${ }^{d} S M F Q-P$ Short Moods and Feelings Questionnaire-Parent version

${ }^{\text {e }}$ SMFQ-C Short Moods and Feelings Questionnaire-Child version

f $S A A I-P$ Separation Anxiety Avoidance Inventory-Parent version

${ }^{9}$ SAAI-C Separation Anxiety Avoidance Inventory-Child version

h ISI-C Insomnia Severity Index-Child and Adolescent version

'AQ-10 Autism Spectrum Quotient Child/Adolescent version-10

${ }^{\mathrm{S} S N A P-I V}$ Swanson, Nolan and Pelham scale-IV

${ }^{\mathrm{k}} E C B I$ Eyberg Child Behavior Inventory

impaired symptoms at follow-up. Descriptive statistics for each of the measures are presented in Tables 1 and 2 .

\section{Agreement between informants}

The overall ICC $(1,3)$ of CGI-S ratings made by clinician, parent and child was 0.57 (95\% CI 0.37-0.74). The ICC $(1,2)$ of clinician and parent CGI-S ratings was 0.69 (0.46-0.83), the ICC $(1,2)$ of clinician and child CGI-S ratings was 0.47 (95\% CI $0.17-0.70)$ and the $\operatorname{ICC}(1,2)$ of parent and child CGI-S ratings was 0.55 (95\% CI $0.26-$ 0.75). Thus, the overall agreement between CGI-S ratings made by clinician, parent and child was only fair.

Regarding the SDQ-P/S for participants $>11$ years $(n=$ $22)$, the ICC $(1,2)$ of parent and child ratings was 0.64 (95\% CI $0.31-0.83)$, representing a moderately good agreement.

The ICC $(1,2)$ of parent and child ratings of the KIDSCREEN-10 was 0.81 (95\% CI 0.65-0.90) and of parent and child ratings of the WSAS-P/Y 0.82 (95\% CI 0.66-0.91), both representing excellent agreements.

The ICC $(1,2)$ of SMFQ-P/C ratings made by parent and child was 0.46 (95\% CI 0.14-0.70), only representing a fair agreement. In contrast, the ICC $(1,2)$ of SAAI-P/C ratings was 0.88 (95\% CI 0.77-0.94), representing an excellent agreement.

\section{Correlations between measures}

Inter-correlations between clinician-rated CGAS and both parent-rated SDQ-P and child-rated SDQ-S were poor, including subscales. There was a fair association between clinician-rated CGI-S and parent-rated total SDQ $(\rho=$ $0.448, p<0.008$ ), but not at a subscale level. The parentrated functional scales KIDSCREEN-10 and WSAS-P had stronger inter-correlations than did the general symptomseverity scale SDQ-P with clinician-rated global symptom and functional scales. There was a moderate-to-strong association between parent-rated KIDSCREEN-10 and clinician-rated CGI-S $(\rho=-0.663, p<0.001)$ and a very strong association between WSAS-P and clinician-rated CGI-S $(\rho=0.811, \mathrm{p}<0.001)$. The same was true for the child-rated versions of the functional scales. See Tables 3 and 4 (subscales available in Tables S1 and S2).

Clinician-rated global symptom and functional scales had moderate associations with clinician-scored CYBOCS but not to child-rated OCI-CV. There was only a fair association between CY-BOCS and OCI-CV $(\rho=$ $0.468, p<0.006)$. See Table S3.

There was a fair-to-moderate association between clinician-rated CGAS and CGI-S and both parent- and child-rated SMFQ-P/C. Symptoms of separation anxiety and sleep disorder were more uncommon in the cohort, 
Table 3 Spearman correlations between clinician-rated global symptom and functional scales and parent-rated KIDSCREEN-10, WSAS-P and SDQ-P and child-rated functional scales KIDSCREEN-10, WSAS-Y and SDQ-S, $n=34$

\begin{tabular}{|c|c|c|c|c|c|c|}
\hline Spearman correlation, $\rho$ & CGAS & CGI-S clinician & CGI-S parent & KIDSCREEN-10 parent & WSAS-P & SDQ-P \\
\hline$\overline{\mathrm{CGAS}^{\mathrm{a}}}$ & 1 & & & & & \\
\hline CGI-S $S^{b}$ clinician & -0.911 & 1 & & & & \\
\hline CGI-S parent & -0.555 & 0.664 & 1 & & & \\
\hline KIDSCREEN-10 parent & 0.567 & -0.663 & -0.308 & 1 & & \\
\hline WSAS-P ${ }^{c}$ & -0.669 & 0.811 & 0.660 & -0.710 & 1 & \\
\hline SDQ-Pd & -0.374 & 0.448 & 0.423 & -0.564 & 0.528 & 1 \\
\hline
\end{tabular}

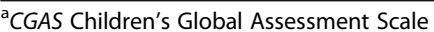

${ }^{\mathrm{b}} \mathrm{CGI}$-S Clinical Global Impression - Severity scale

'WSAS-P Work and Social Adjustment Scale Parent version

${ }^{\mathrm{d}}$ SDQ-P Strengths and Difficulties Questionnaire Parent-rated

and inter-correlations between the symptom-specific measures SAAI-C and ISI-C and the global symptom and functional scales were lower. See Table 5.

There was a fair-to-moderate association between CGAS and CGI-S and AQ-10, ECBI and SNAP-IV, specifically on the SNAP-IV inattention subscale. ECBI had a very strong association to SNAP-IV, highest on the SNAP-IV total but also on hyperactivity and conduct subscales, as expected. See Table 6.

In summary, the global clinician-rated symptom and functional measures tended to have stronger intercorrelations with parent- and child-rated functional measures than with symptom-specific measures.

\section{Discussion}

In this study we analyzed data from a PANS cohort that had been followed-up for 2-5 years after initial presentation [5]. We examined the correspondence between clinician, parent and child measures of global symptom severity, adaptive functioning and specific psychiatric symptoms. This is critical because it is still unclear how to best measure the complex symptom presentation of the syndrome. Using the appropriate outcome measures has important implications for both clinical practice and the design of clinical trials.

Overall, median ratings for measures assessing global symptom severity and adaptive functioning indicated low symptom burden and a rather high level of everyday functioning in our sample. However, there was a large variability in the data, particularly in the symptomspecific measures, reflecting the heterogeneity of symptom presentations and clinical courses that are characteristic of the syndrome. These findings confirm and extend the findings of our previous study on the same cohort [5]. Specifically, we had previously reported that approximately one third of participants in the follow-up study had clinically significant symptoms and required additional treatment.

CGI-S is a gold standard measure of psychiatric illness severity, most frequently assessed by the clinician. The modest agreement between CGI-S ratings across informants in our sample suggests that it may be helpful complementing the clinician rating with ratings made by the parent and child. Overall, agreement between ratings made by parent and child were excellent for functional scales, but only fair-to-moderate for global symptom severity and symptom-specific scales, with the exception of

Table 4 Spearman correlations between clinician-rated global symptom and functional scales and child-rated KIDSCREEN-10, WSAS$Y$ and SDQ-S, $n=22$ (excludes participants $<11$ years)

\begin{tabular}{|c|c|c|c|c|c|c|}
\hline Spearman correlation, $\rho$ & CGAS & CGI-S clinician & CGI-S child & KIDSCREEN-10 child & WSAS-Y & $\overline{S D Q-S}$ \\
\hline $\mathrm{CGAS}^{\mathrm{a}}$ & 1 & & & & & \\
\hline CGI-S ${ }^{\mathrm{b}}$ clinician & -0.929 & 1 & & & & \\
\hline CGI-S child & -0.511 & 0.473 & 1 & & & \\
\hline KIDSCREEN-10 child & 0.627 & -0.626 & -0.257 & 1 & & \\
\hline WSAS-Yc & -0.570 & 0.640 & 0.315 & -0.569 & 1 & \\
\hline$S D Q-S^{d}$ & -0.304 & 0.215 & 0.344 & -0.195 & 0.196 & 1 \\
\hline
\end{tabular}

${ }^{a}$ CGAS Children's Global Assessment Scale

${ }^{\mathrm{b}}$ CGI-S Clinical Global Impression - Severity scale

'WSAS-Y Work and Social Adjustment Scale Youth version

${ }^{\mathrm{d}} S D Q-S$ Strengths and Difficulties Questionnaire Self- rated 
Table 5 Spearman correlations between clinician-rated global and functional scales and SMFQ-P/C, SAAI-P/C and ISI-C, $n=30$

\begin{tabular}{|c|c|c|c|c|c|c|c|}
\hline Spearman correlation, $\rho$ & CGAS & CGI-S clinician & SMFQ-P & SMFQ-C & SAAI-P & SAAI-C & ISI-C \\
\hline$\overline{\mathrm{CGAS}^{a}}$ & 1 & & & & & & \\
\hline $\mathrm{CGI}^{\mathrm{b}} \mathrm{b}^{\mathrm{c}}$ clinician & -0.904 & 1 & & & & & \\
\hline SMFQ-PC & -0.447 & 0.516 & 1 & & & & \\
\hline SMFQ-C & -0.582 & 0.457 & 0.527 & 1 & & & \\
\hline SAAI-Pd & -0.362 & 0.485 & 0.461 & 0.146 & 1 & & \\
\hline SAAI-C & -0.241 & 0.364 & 0.258 & 0.871 & 0.125 & 1 & \\
\hline$|S|-C^{e}$ & -0.198 & 0.297 & 0.362 & 0.297 & 0.225 & 0.253 & 1 \\
\hline
\end{tabular}

${ }^{a}$ CGAS Children's Global Assessment Scale

${ }^{\mathrm{b}}$ CGI-S Clinical Global Impression - Severity scale

'SMFQ-P/C Short Moods and Feelings Questionnaire-Parent/Child version

${ }^{\mathrm{S} S A A I-P / C}$ Separation Anxiety Avoidance Inventory-Parent/Child version

eISI-C Insomnia Severity Index Child/Adolescent version

the separation anxiety measure, which had excellent agreement between informants.

As expected, because of the previously mentioned heterogeneity of symptom presentations, global clinicianrated symptom and functional measures tended to have stronger inter-correlations with parent- and child-rated functional measures than with symptom-specific ones.

Parent- and child-rated functional scales KIDSCREEN10 and WSAS-P/Y correlated well with clinician-rated global symptom and functional scales, and the agreements between ratings made by parent and child were excellent. Despite both scales being useful in the study, KIDSCREEN-10 may be more easily accessible to a younger patient group. Multiple parents commented on the suitability of the WSAS-P/Y, and indicated that its items may be less suitable for the younger patients. By contrast, the KIDSCREEN-10 was perceived as simple and straightforward for both younger children and teenagers.

Somewhat surprisingly, SDQ-P/S seemed to have weak inter-correlations with global symptom and functional scales and the agreement between informants was only moderate. This may be due to SDQ-P/S being more symptom-oriented than the other global measures used in the study. Results suggest that it may be less clinically useful in this particular patient group, but it should also be noted that the SDQ impact supplement was not used and therefore is not included in our analyses.

Obsessive-compulsive symptoms are part of main PANS criteria but were surprisingly rare in our sample at follow-up. Assessing obsessive-compulsive symptoms with a self-rated scale as a complement to CY-BOCS may not add a lot of information within the PANS patient group at follow-up. At onset, OCD is generally a

Table 6 Spearman correlations between clinician-rated global and functional scales and AQ-10, SNAP-IV and ECBI, $n=30$

\begin{tabular}{|c|c|c|c|c|c|c|c|c|c|}
\hline Spearman correlation, $\rho$ & CGAS & $\begin{array}{l}\text { CGI-S } \\
\text { clinician }\end{array}$ & AQ-10 & SNAP-IV & $\begin{array}{l}\text { SNAP-IV } \\
\text { inattention }\end{array}$ & $\begin{array}{l}\text { SNAP-IV } \\
\text { hyper }\end{array}$ & $\begin{array}{l}\text { SNAP-IV } \\
\text { conduct }\end{array}$ & ECBI & $\begin{array}{l}\text { ECBI } \\
\text { problem }\end{array}$ \\
\hline$\overline{C_{G A S}}$ & 1 & & & & & & & & \\
\hline CGI-S $S^{b}$ clinician & -0.904 & 1 & & & & & & & \\
\hline$A Q-10^{c}$ & -0.421 & 0.558 & 1 & & & & & & \\
\hline SNAP-IV ${ }^{d}$ & -0.398 & 0.511 & 0.330 & 1 & & & & & \\
\hline SNAP-IV inattention & -0.463 & 0.562 & 0.289 & 0.813 & 1 & & & & \\
\hline SNAP-IV hyper & -0.238 & 0.300 & 0.220 & 0.916 & 0.652 & 1 & & & \\
\hline SNAP-IV conduct & -0.261 & 0.300 & 0.240 & 0.760 & 0.391 & 0.668 & 1 & & \\
\hline$\left.E C B\right|^{e}$ & -0.331 & 0.432 & 0.378 & 0.874 & 0.660 & 0.809 & 0.745 & 1 & \\
\hline ECBI problem & -0.373 & 0.503 & 0.584 & 0.813 & 0.614 & 0.720 & 0.710 & 0.937 & 1 \\
\hline
\end{tabular}

${ }^{a}$ CGAS Children's Global Assessment Scale

${ }^{\mathrm{b}} \mathrm{CGI}$-S Clinical Global Impression - Severity scale

${ }^{C} A Q-10$ Autism Spectrum Quotient Child/Adolescent version-10

dSNAP-IV Swanson, Nolan and Pelham scale-IV

${ }^{\mathrm{e}} E C B I$ Eyberg Child Behavior Inventory 
more pervasive part of the symptom presentation, and more time should be devoted to a comprehensive OCD assessment.

We did not include a measure specifically measuring eating disorder symptoms because, in our clinical experience, these tend to be OCD-related and without the defining features of a typical eating disorder such as fears of gaining weight (resembling avoidant/restrictive food avoidance disorder). For selected patients with eating difficulties, it may be useful to measure these symptoms in order to track their improvement.

The agreement between SMFQ-P/C ratings made by parent and child was only fair, indicating the importance of having both parent- and child ratings of depression and thus avoid underestimating these symptoms in PANS patients. Conversely, the agreement between SAAI-P/C ratings made by parent and patient was excellent, suggesting that either parent or child ratings may suffice for clinical purposes.

Previous longitudinal data have shown a high comorbidity with neuropsychiatric disorders, combined with intensification of related symptoms during PANS flares $[5,45]$. We therefore recommend measures that can screen for, and assess the severity of, autistic behaviors, inattention, hyperactivity and conduct problems when following up PANS. In our sample ECBI had a very strong association to SNAP-IV, suggesting that the simpler SNAP-IV may sufficiently cover the patients' oppositional behaviors for clinical purposes. When detecting potentially severe oppositional defiant behaviors, ECBI can be used as a complement.

Our study has some limitations. First, we analyzed data from a small sample of patients from a single clinic. Second, the age range was such that the results of the child-rated measures should be interpreted with caution; despite our efforts, it is possible that the younger children received help from their parents to fill in their questionnaires. Third, we were not able to calculate internal consistency of the scales included in this study (only total scores were available). We could thus not examine the psychometric properties of the scales in this particular sample. Future studies would benefit from conducting such psychometric analyses.

\section{Summary}

Clinical experience and the results from our followup study suggest that it is important to include clinician-, parent- and child ratings in the assessment of PANS, as a single perspective is unlikely to capture the full complexity of the syndrome. Brief, general measures assessing global disease severity and adaptive functioning, are clinically helpful and should be
Table 7 Proposed rating scale protocol

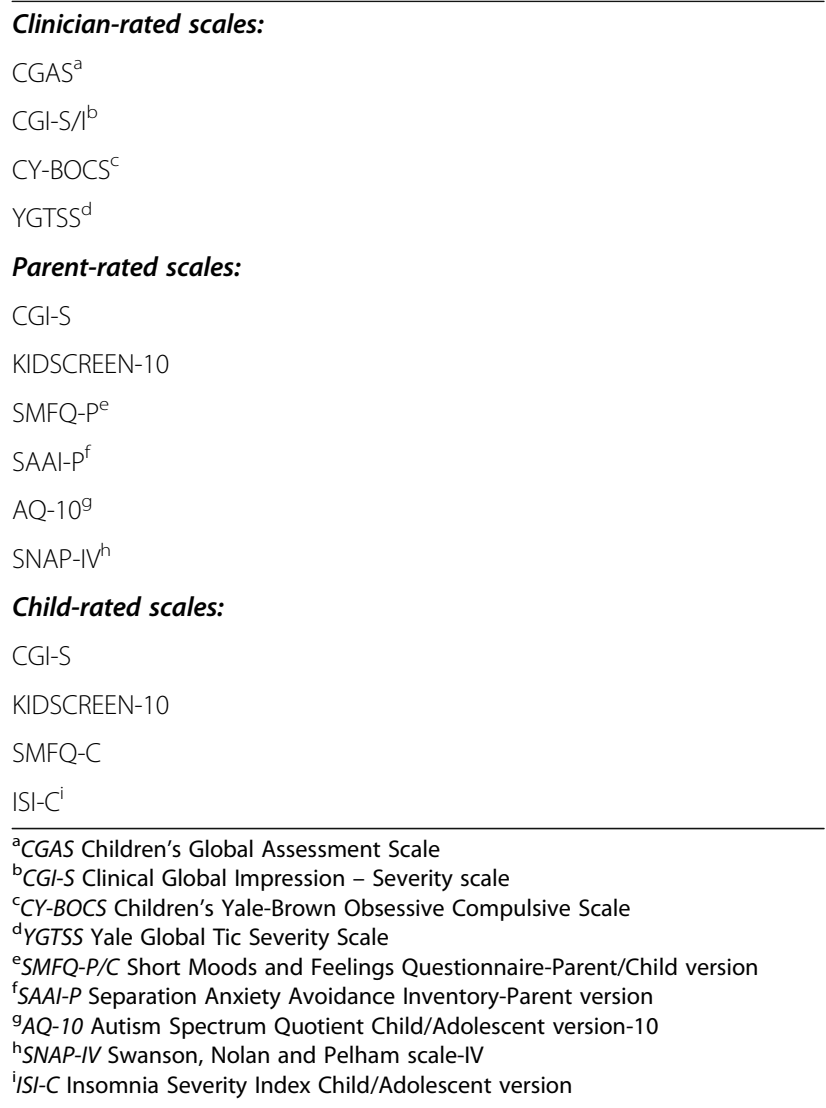

used but should be complemented by symptomspecific scales representative of the core symptoms in PANS, such as OCD, anxiety, depression and behavioral problems. However, their exclusive use is problematic as the natural course of the syndrome is such that some patients may not have specific symptoms to rate at follow-up. Furthermore, it is important that the assessment is straightforward and as brief as possible. Based on our experience, we recommend the use of a core battery of clinician-, parent- and childrated measures in both clinical practice and in clinical trials (Table 7). The proposed core battery of measures will provide a broad evaluation of PANS-related symptoms, but can be complemented with further symptom-specific measures when needed.

\section{Supplementary Information}

The online version contains supplementary material available at https://doi. org/10.1186/s12888-021-03450-5.

Additional file 1.

Additional file 2.

Additional file 3.

Additional file 4.

Additional file 5. 


\section{Acknowledgements}

The authors thank the children and their parents who participated in the research despite the ongoing COVID-19 pandemic.

\section{Authors' contributions}

The study was designed by CDV and DMC. Statistical analyses were performed by CDV, under supervision of DR and EH. CDV drafted the manuscript, under the supervision of DMC. The manuscript was reviewed by all authors who also read and approved the final version.

\section{Funding}

Region Stockholm, Jane and Dan Olsson Foundations, Fonden för Rehabilitering och Medicinsk forskning (FRF-stiftelsen), Fonden för Psykisk Hälsa, Drottning Silvias Jubileumsfond. Open Access funding provided by Karolinska Institute.

\section{Availability of data and materials}

The data are pseudonymised according to national (Swedish) and EU legislation, and cannot be anonymised and published in an open repository. The data can be made available upon reasonable request to Principal Investigator Professor David Mataix-Cols (david.mataix.cols@ki.se) on a case by case basis according to the current legislation and ethical permits.

\section{Declarations}

\section{Ethics approval and consent to participate}

The study was approved by the Regional Ethics Review Board in Stockholm (reference number EPN 2015/1977-31/4 (2019-02132)). Written informed consent was obtained from all individual participants. All procedures performed in the study were in accordance with the 1964 Declaration of Helsinki and its later amendments.

\section{Consent for publication}

Not applicable.

\section{Competing interests}

The authors declare that they have no conflict of interest

\section{Author details}

${ }^{1}$ Centre for Psychiatry Research, Department of Clinical Neuroscience, Karolinska Institutet, Stockholm, Sweden. ${ }^{2}$ Stockholm Health Care Services, Region Stockholm, CAP Research Center, Gävlegatan 22, SE-113 30, Stockholm, Sweden. ${ }^{3}$ Moment Psykologi, Drottninggatan 99, 11360 Stockholm, Sweden.

\section{Received: 29 April 2021 Accepted: 26 August 2021}

Published online: 04 October 2021

\section{References}

1. Swedo S, Leckman J, Rose N. From research subgroup to clinical syndrome: modifying the PANDAS criteria to describe PANS (pediatric acute-onset neuropsychiatric syndrome). Pediatr Therapeut. 2012;2(2):113. https://doi. org/10.4172/2161-0665.1000113.

2. Frankovich J, Thienemann M, Pearlstein J, Crable A, Brown K, Chang K. Multidisciplinary clinic dedicated to treating youth with pediatric acuteonset neuropsychiatric syndrome: presenting characteristics of the first 47 consecutive patients. J Child Adolesc Psychopharmacol. 2015;25(1):38-47. https://doi.org/10.1089/cap.2014.0081

3. Gromark C, Harris RA, Wickström R, Horne A, Silverberg-Mörse M, Serlachius $E$, et al. Establishing a pediatric acute-onset neuropsychiatric syndrome clinic: baseline clinical features of the pediatric acute-onset neuropsychiatric syndrome cohort at Karolinska Institutet. J Child Adolesc Psychopharmacol. 2019;29(8):625-33. https://doi.org/10.1089/cap.2018.0127.

4. Sigra S, Hesselmark E, Bejerot $S$. Treatment of PANDAS and PANS: a systematic review. Neurosci Biobehav Rev. 2018;86:51-65. https://doi.org/1 0.1016/..neubiorev.2018.01.001.

5. Gromark C, Hesselmark E, Djupedal IG, Silverberg M, Horne A, Harris RA, et al. A two-to-five year follow-up of a pediatric acute-onset neuropsychiatric syndrome cohort. Child Psychiatry Hum Dev. 2021:1-11. https://doi.org/10.1007/s10578-021-01135-4.
6. Murphy TK, Patel PD, McGuire JF, Kennel A, Mutch PJ, Parker-Athill EC, et al. Characterization of the pediatric acute-onset neuropsychiatric syndrome phenotype. J Child Adolesc Psychopharmacol. 2015;25(1):14-25. https://doi. org/10.1089/cap.2014.0062

7. Chang K, Frankovich J, Cooperstock M, Cunningham MW, Latimer ME, Murphy TK, et al. Clinical evaluation of youth with pediatric acute-onset neuropsychiatric syndrome (PANS): recommendations from the 2013 PANS consensus conference. J Child Adolesc Psychopharmacol. 2015;25(1):3-13. https://doi.org/10.1089/cap.2014.0084.

8. Johnson M, Fernell E, Preda I, Wallin L, Fasth A, Gillberg C, et al. Paediatric acute-onset neuropsychiatric syndrome in children and adolescents: an observational cohort study. Lancet Child Adolesc Health. 2019;3(3):175-80. https://doi.org/10.1016/S2352-4642(18)30404-8.

9. Swedo S KM, Latimer B, Leckman J. Pediatric Acute Neuropsychiatric Symptom Scale https://pandasnetwork.org/wp-content/uploads/2018/11/pa ndas_pans_scale.pdf. Accessed March 11, 2021.

10. Bejerot S, Hesselmark E, Humble M. Abstract \# 1786 The PsychoNeurolnflammatory related Signs and Severity Inventory (PNISSI). Brain Behav Immun. 2016;57:e23.

11. Rapp AM, Bergman RL, Piacentini J, McGuire JF. Evidence-based assessment of obsessive-compulsive disorder. J Central Nervous Syst Dis. 2016;8:13-29. https://doi.org/10.4137/JCNSD.S38359.

12. Storch EA, Murphy TK, Adkins JW, Lewin AB, Geffken GR, Johns NB, et al. The children's Yale-Brown obsessive-compulsive scale: psychometric properties of child- and parent-report formats. J Anxiety Disord. 2006;20(8): 1055-70. https://doi.org/10.1016/j.janxdis.2006.01.006.

13. Leckman JF, Riddle MA, Hardin MT, Ort SI, Swartz KL, Stevenson J, et al. The Yale global tic severity scale: initial testing of a clinician-rated scale of tic severity. J Am Acad Child Adolesc Psychiatry. 1989;28(4):566-73. https://doi. org/10.1097/00004583-198907000-00015.

14. Williams KA, Swedo SE, Farmer CA, Grantz H, Grant PJ, D'Souza P, et al. Randomized, Controlled Trial of Intravenous Immunoglobulin for Pediatric Autoimmune Neuropsychiatric Disorders Associated With Streptococcal Infections. J Am Acad Child Adolesc Psychiatry. 2016;55(10):860-867.e862.

15. Guy W. ECDEU Assessment Manual for Psychopharmacology - Revised. In: U. S. Department of Healt EaW, Public Health Service, Mental Health Administration. Rockville, MD.: NIMH Psychopharmacological Research Branch, Diviosion of Extramural Research Programs; 1976.

16. Berk M, Ng F, Dodd S, Callaly T, Campbell S, Bernardo M, et al. The validity of the CGI severity and improvement scales as measures of clinical effectiveness suitable for routine clinical use. J Eval Clin Pract. 2008;14(6): 979-83. https://doi.org/10.1111/j.1365-2753.2007.00921.x.

17. Smedje H, Broman JE, Hetta J, von Knorring AL. Psychometric properties of a Swedish version of the "strengths and difficulties questionnaire". Eur Child Adolesc Psychiatry. 1999;8(2):63-70. https://doi. org/10.1007/s007870050086.

18. Malmberg M, Rydell AM, Smedje H. Validity of the Swedish version of the strengths and difficulties questionnaire (SDQ-Swe). Nordic J Psychiatry. 2003; 57(5):357-63. https://doi.org/10.1080/08039480310002697.

19. Schorre $B E$, Vandvik IH. Global assessment of psychosocial functioning in child and adolescent psychiatry. A review of three unidimensional scales (CGAS, GAF, GAPD). Eur Child Adolesc Psychiatry. 2004;13(5):273-86. https:// doi.org/10.1007/s00787-004-0390-2.

20. Endicott J, Spitzer RL, Fleiss JL, Cohen J. The global assessment scale. A procedure for measuring overall severity of psychiatric disturbance. Arch Gen Psychiatry. 1976;33(6):766-71. https://doi.org/10.1001/archpsyc.1976.01 770060086012.

21. Shaffer D, Gould MS, Brasic J, Ambrosini P, Fisher P, Bird H, et al. A children's global assessment scale (CGAS). Arch Gen Psychiatry. 1983;40(11):1228-31. https://doi.org/10.1001/archpsyc.1983.01790100074010.

22. Europe TKG. The KIDSCREEN questionnaires - quality of life questionnaires for children and adolescents. Lengerich: Pabst Science Publishers; 2006.

23. Ravens-Sieberer U, Erhart M, Rajmil L, Herdman M, Auquier P, Bruil J, et al. Reliability, construct and criterion validity of the KIDSCREEN-10 score: a short measure for children and adolescents' well-being and health-related quality of life. Qual Life Res. 2010;19(10):1487-500. https://doi.org/10.1007/ s11136-010-9706-5.

24. Mundt JC, Marks IM, Shear MK, Greist JH. The work and social adjustment scale: a simple measure of impairment in functioning. Br J Psychiatry. 2002; 180(5):461-4. https://doi.org/10.1192/bjp.180.5.461. 
25. Jassi A, Lenhard F, Krebs G, Gumpert M, Jolstedt M, Andrén P, et al. The work and social adjustment scale, youth and parent versions: psychometric evaluation of a brief measure of functional impairment in young people. Child Psychiatry Hum Dev. 2020;51(3):453-60. https://doi.org/10.1007/s1 0578-020-00956-Z.

26. Storch EA, McGuire JF, Wu MS, Hamblin R, Mclngvale E, Cepeda SL, et al. Development and psychometric evaluation of the Children's Yale-Brown obsessive-compulsive scale second edition. J Am Acad Child Adolesc Psychiatry. 2019;58(1):92-8. https://doi.org/10.1016/j.jaac.2018.05.029.

27. McGuire JF, Piacentini J, Storch EA, Murphy TK, Ricketts EJ, Woods DW, et al. A multicenter examination and strategic revisions of the Yale global tic severity scale. Neurology. 2018;90(19):1711-9. https://doi.org/10.1212/WNL. 0000000000005474.

28. Foa EB, Coles M, Huppert JD, Pasupuleti RV, Franklin ME, March J. Development and validation of a child version of the obsessive compulsive inventory. Behav Ther. 2010;41(1):121-32. https://doi.org/10.1016/j.beth.2009. 02.001.

29. Aspvall K, Cervin M, Andrén P, Perrin S, Mataix-Cols D, Andersson E. Validity and clinical utility of the obsessive compulsive inventory - child version: further evaluation in clinical samples. BMC Psychiatry. 2020;20(1):42. https:// doi.org/10.1186/s12888-020-2450-7.

30. Kent L, Vostanis P, Feehan C. Detection of major and minor depression in children and adolescents: evaluation of the mood and feelings questionnaire. J Child Psychol Psychiatry Allied Discip. 1997;38(5):565-73. https://doi.org/10.1111/j.1469-7610.1997.tb01543.x.

31. Jarbin H, Ivarsson T, Andersson M, Bergman H, Skarphedinsson G. Screening efficiency of the mood and feelings questionnaire (MFQ) and short mood and feelings questionnaire (SMFQ) in Swedish help seeking outpatients. PLoS One. 2020;15(3):e0230623. https://doi.org/10.1371/journal.pone.0230623.

32. In-Albon T, Meyer AH, Schneider S. Separation anxiety avoidance inventorychild and parent version: psychometric properties and clinical utility in a clinical and school sample. Child Psychiatry Hum Dev. 2013;44(6):689-97. https://doi.org/10.1007/s10578-013-0364-z.

33. Bastien $\mathrm{CH}$, Vallières $\mathrm{A}$, Morin $\mathrm{CM}$. Validation of the insomnia severity index as an outcome measure for insomnia research. Sleep Med. 2001;2(4):297307. https://doi.org/10.1016/S1389-9457(00)00065-4.

34. Chung KF, Kan KK, Yeung WF. Assessing insomnia in adolescents: comparison of insomnia severity index, Athens insomnia scale and sleep quality index. Sleep Med. 2011;12(5):463-70. https://doi.org/10.1016/j.sleep.2 010.09.019.

35. Allison C, Auyeung B, Baron-Cohen S. Toward brief "Red Flags" for autism screening: The Short Autism Spectrum Quotient and the Short Quantitative Checklist for Autism in toddlers in 1,000 cases and 3,000 controls [corrected]. J Am Acad Child Adolesc Psychiatry. 2012;51(2):202-212.e207.

36. Bussing R, Fernandez M, Harwood M, Wei H, Garvan CW, Eyberg SM, et al. Parent and teacher SNAP-IV ratings of attention deficit hyperactivity disorder symptoms: psychometric properties and normative ratings from a school district sample. Assessment. 2008;15(3):317-28. https://doi.org/10.11 77/1073191107313888.

37. Swanson JM, Kraemer HC, Hinshaw SP, Arnold LE, Conners CK, Abikoff HB, et al. Clinical relevance of the primary findings of the MTA: success rates based on severity of ADHD and ODD symptoms at the end of treatment. J Am Acad Child Adolesc Psychiatry. 2001;40(2):168-79. https://doi.org/10.1 097/00004583-200102000-00011.

38. SNAP-IV Swedish version. Available at: http://www.sfbup.se/wp-content/ uploads/2020/04/SNAP-IV-SFBUP.pdf. Accessed February 24, 2021.

39. Axberg U, Johansson Hanse J, Broberg AG. Parents' description of conduct problems in their children - a test of the Eyberg child behavior inventory (ECBI) in a Swedish sample aged 3-10. Scand J Psychol. 2008:49(6):497-505. https://doi.org/10.1111/j.1467-9450.2008.00670.x.

40. Burns GL, Patterson DR. Factor structure of the Eyberg child behavior inventory: a parent rating scale of oppositional defiant behavior toward adults, inattentive behavior, and conduct problem behavior. J Clin Child Psychol. 2000;29(4):569-77. https://doi.org/10.1207/S15374424JCCP2904_9.

41. Koo TK, Li MY. A guideline of selecting and reporting Intraclass correlation coefficients for reliability research. J Chiropractic Med. 2016;15(2):155-63. https://doi.org/10.1016/j.jcm.2016.02.012.

42. Ciccheti. Guidelines, criteria, and rules of thumb for evaluating normed and standardized assess- ment instruments in psychology. Psychol Assess. 1994; $(6(4)): 284-90$.
43. Akoglu H. User's guide to correlation coefficients. Turkish J Emerg Med. 2018;18(3):91-3. https://doi.org/10.1016/j.tjem.2018.08.001.

44. Fält E, Wallby T, Sarkadi A, Salari R, Fabian H. Agreement between mothers', fathers', and teachers' ratings of behavioural and emotional problems in 35-year-old children. PLoS One. 2018;13(11):e0206752. https://doi.org/10.13 71/journal.pone.0206752

45. Leon J, Hommer R, Grant P, Farmer C, D'Souza P, Kessler R, et al. Longitudinal outcomes of children with pediatric autoimmune neuropsychiatric disorder associated with streptococcal infections (PANDAS). Eur Child Adolesc Psychiatry. 2018;27(5):637-43. https://doi.org/1 0.1007/s00787-017-1077-9.

\section{Publisher's Note}

Springer Nature remains neutral with regard to jurisdictional claims in published maps and institutional affiliations.
Ready to submit your research? Choose BMC and benefit from:

- fast, convenient online submission

- thorough peer review by experienced researchers in your field

- rapid publication on acceptance

- support for research data, including large and complex data types

- gold Open Access which fosters wider collaboration and increased citations

- maximum visibility for your research: over $100 \mathrm{M}$ website views per year

At BMC, research is always in progress.

Learn more biomedcentral.com/submissions 